\title{
Novos significados para educação profissional e tecnológica no instituto federal sul-rio-grandense: a política de criação dos institutos
}

\author{
New meanings for professional and technological education in the federal \\ institute sul-rio-grandense: the expansion policy of institutes \\ Nuevos significados para la educación profesional y tecnológica en el instituto \\ federal del rio grande do sul: la política de creación de los institutos \section{ÁLVARO MOREIRA HYPÓLITO} \\ JAIR JONKO ARAUJO
}

Resumo: Este trabalho analisa as concepções de gestão na Educação Infantil, especialmente a democrática, tendo por referência os artigos produzidos na Revista Brasileira de Política e Administração da Educação (RBPAE) no período de 2000 a 2012. É possível afirmar que os estudos sobre gestão educacional privilegiaram como temática o Ensino Fundamental, o Ensino Médio e o Ensino Superior, o que nos permite dizer que a Educação Infantil ainda ocupa lugar marginal nas discussões do campo da gestão. Além disso, a produção analisada não apresenta discussão aprofundada sobre a gestão democrática nas creches e pré-escolas.

Palavras-chave: Teoria do discurso; educação profissional e tecnológica; institutos federais; significados.

\begin{abstract}
This paper discusses meanings induced via by official policy of implementation of Federal Institutes, their reception into the institutional documentation and production of meanings by managers. The analysis of official documentation of MEC, IFSul and interviews with managers applies some concepts of the Laclau's Discourse Theory. We conclude that there is a complex process of acceptance and rejection of meanings, that there is a consolidated teaching myth in the federal system, and there is no hegemonic institutional policies for research and extension yet.
\end{abstract}

Keywords: Discourse theory; professional and technological education; federal institutes; meanings.

Resumen: Este trabajo discute los significados inducidos por la política oficial de creación de los Institutos Federales, su recepción en la documentación institucional y la producción de sentidos por los gestores. El análisis de la documentación oficial del MEC y del IFSul y de las entrevistas con los gestores se lleva a cabo mediante la aplicación de conceptos de la Teoría del Discurso de Laclau. Llegamos a la conclusión de que existe un complejo proceso de acogida y rechazo de sentidos, que hay un mito de enseñanza consolidado en el sistema federal y que, todavía, no hay políticas hegemónicas institucionales para la investigación y la extensión. 
Palabras clave: Teoría del discurso; educación profesional y tecnológica; institutos federales; significados.

\section{INTRODUÇÃO}

Ao longo do tempo, como parte dos movimentos que a educação profissional realiza para acompanhar as constantes mudanças sociais das formas de produção, diferentes formas de organização vêm sendo adotadas para o conjunto de instituições federais dedicadas à educação profissional e tecnológica. Atualmente, a Lei 11.892/2008 (BRASIL, 2008) regula a organização da rede federal de educação profissional, científica e tecnológica (RFEPT).

$\mathrm{O}$ atual modelo organizacional tem por base os Institutos Federais de Educação Ciência e Tecnologia (IFs), os quais foram constituídos pela integração de diferentes instituições federais de educação tecnológica existentes em um determinado território: centros federais de educação tecnológica, escolas técnicas federais, escolas agrotécnicas federais e escolas técnicas vinculadas a universidades federais.

Os IFs possuem natureza de autarquias federais (detentoras de autonomia administrativa, patrimonial, financeira, didático-pedagógica e disciplinar), são multicampi (compostos por uma reitoria e diversos campi, em geral localizados em diferentes municípios de determinada região), atuam em diversos níveis e modalidades de ensino (da educação básica à superior, nas modalidades presencial, a distância, educação de jovens e adultos e profissional) e também nas áreas de pesquisa e extensão. Possuem, portanto, um espaço diferenciado de autonomia e, embora a reestruturação seja recente, em geral, são instituições com longa trajetória institucional.

Pode-se avaliar que a criação dos IFs e a expansão do número de escolas e da oferta de cursos apresentam-se como novos elementos de tensionamento das políticas educacionais para Educação Profissional e Tecnológica (EPT) nas instituições federais de educação profissional: os discursos do Ministério da Educação (MEC) apontam para a criação de uma nova identidade ${ }^{1}$ para a rede federal, conforme se pode interpretar a seguir:

\footnotetext{
Mais que tudo, a decisão de estabelecer os Institutos Federais como política pública representa trabalhar na superação da representação existente (a de subordinação quase absoluta ao poder econômico) e estabelecer sintonia com outras esferas do
} 1 Neste trabalho adota-se o conceito de identidade conforme a Teoria do Discurso, que será
apresentada na próxima seção.

248 - RBPAE - v. 32, n. 1, p. 247 - 265 jan./abr. 2016 
poder público e da sociedade, na construção de um projeto mais amplo para a educação pública, com singularidades que lhe são bastante próprias, passando a atuar como uma rede social de educação profissional e tecnológica. (MEC/SETEC, 2008, p. 17)

Para estudar como esse processo de reestruturação vem sendo construído institucionalmente, realizou-se uma investigação sobre quais sentidos estão sendo produzidos na política curricular do Instituto Federal Sul-rio-grandense (IFSul) ${ }^{2}$, a partir da criação dos IFs (Araujo, 2013).

Este artigo recorta parte dessa pesquisa com o objetivo de discutir que sentidos são induzidos por tal política, como são acolhidos nos documentos institucionais e como gestores do IFSul constroem sentidos em seus processos cotidianos de (re)construção dessa política, quais suas motivações, como são construídas as relações e os movimentos de resistência. Enfim, discute, em uma instituição com privilegiado espaço de autonomia, possibilidades e limitações da autonomia institucional para a construção de processos de gestão diferenciados.

A coleta dos dados de campo buscou reunir uma empiria em diferentes contextos: para se investigarem as propostas do MEC tomaram-se por referência documentos legais e publicações oficiais assinadas pelo Ministério e, para compreender os movimentos institucionais no IFSul, investigou-se a reitoria agente na construção das políticas no IFSul - e a direção geral do campus - agente na construção das políticas no âmbito local; nesse caso, as investigações ocorreram a partir de documentos institucionais e da interação com diferentes atores sociais que vivenciam o ambiente social investigado em diferentes contextos.

Assim, as questões ficaram amarradas à subjetividade dos envolvidos na pesquisa, os quais atribuem sentido ao mundo, o que exige uma postura interpretativa do pesquisador, caracterizando-se, portanto, como uma pesquisa qualitativa (FLICK, 2009). Ao adotar a perspectiva discursiva na abordagem na pesquisa, procurou-se destacar os processos de fixação e deslocamentos de sentidos na construção da política curricular na instituição.

No MEC, o foco de estudo foi a Secretaria de Educação Profissional e Tecnológica (SETEC) que regula as políticas para EPT. Os documentos oficiais do MEC são basicamente de duas categorias: (i) os documentos legais que tratam da criação e estruturação dos institutos e (ii) documentos que interpretam a política, publicados durante o processo de constituição dos IFs, buscando consolidar determinados sentidos. Neste último grupo há documentos publicados com assinatura da SETEC, em geral assinados pelo secretário ou por membros de

2 O IFSul é um dos três IFs do RS. É uma Instituição multicampi, composta pela Reitoria e pelos campi Pelotas, Pelotas/Visconde da Graça, Sapucaia do Sul, Passo Fundo, Charqueadas, Camaquã, Bagé, Venâncio Aires, Santana do Livramento, Lajeado, Gravataí e Sapiranga (os três últimos em processo de implantação). 
sua equipe, e documentos publicados em revistas, assinados por professores/ gestores da rede. Na Tabela 1 podem ser observados os documentos utilizados, todos disponíveis na internet.

Tabela 1 - Documentos oficiais do MEC.

\begin{tabular}{|c|c|}
\hline Documento & Tipo de documento \\
\hline Lei 11892/2008 & Lei Federal \\
\hline EM Interministerial 00118/ 2008/MP/MEC & Exposição de Motivos do MPOG/MEC \\
\hline Decreto 6095/2007 & Decreto Federal \\
\hline $\begin{array}{c}\text { Chamada pública de propostas para constituição dos } \\
\text { IFETs }\end{array}$ & Chamada pública do MEC \\
\hline Lei 11892/2008 comentada & Publicação da SETEC \\
\hline Concepções e diretrizes dos IFs & Publicação da SETEC \\
\hline EPT & Publicação da SETEC \\
\hline $\begin{array}{c}\text { SETEC/MEC: Bases para uma Política Nacional de } \\
\text { Os IFETs e o projeto nacional }\end{array}$ & Publicação da SETEC \\
\hline $\begin{array}{c}\text { Os Institutos Federais: uma revolução na Educação } \\
\text { Profissional e Tecnológica }\end{array}$ & Publicação da SETEC \\
\hline $\begin{array}{c}\text { A produção de ciência e tecnologia nos Institutos } \\
\text { Federais, 100 anos de aprendizagem }\end{array}$ & Artigo em revista sobre EPT \\
\hline IFET - Construção da identidade & Artigo em revista sobre EPT \\
\hline $\begin{array}{c}\text { Educação profissional em sintonia com a realidade } \\
\text { local }\end{array}$ & Coletânea de Artigos \\
\hline
\end{tabular}

Compõem a documentação do IFSul: o Estatuto, o Regimento Geral, os Regimentos Internos dos campi (um documento por campus), a Organização Didática, o Projeto Pedagógico Institucional e a Proposta de Adesão aos Institutos Federais. Destaca-se que alguns documentos foram construídos após a transformação em instituto; outros, entretanto, são documentos previamente construídos que tiveram apenas correções textuais, dentre os quais se destaca o Projeto Pedagógico Institucional, aprovado em 2006.

Os gestores dos campi e da Reitoria entrevistados são todos professores, com diferente titulação e predominantemente do gênero masculino. No grupo de gestores dos Campi foram entrevistados cinco diretores-gerais e três gestores de ensino, pesquisa e extensão, em cinco campi diferentes (Bagé, Camaquã, Charqueadas, Pelotas e Sapucaia do Sul); no grupo de Gestão da Reitoria foram entrevistados o reitor, quatro pró-reitores e três diretores sistêmicos. Esse conjunto de 16 entrevistas, transcritas para análise, totalizou aproximadamente 15 horas. 
Atualmente, em virtude de processos eleitorais, alguns desses entrevistados deixaram de ocupar suas funções de gestão. Destaca-se, entretanto, que oito continuam ocupando funções de gestão na reitoria e nos diferentes campi; dos demais, dois ocupam função de gestão em outras instituições, três, por serem servidores efetivos, retornaram à atividade docente e outros três se aposentaram.

Com base nos fundamentos da Teoria do Discurso proposta por Ernesto Laclau, o trabalho discutirá os sentidos presentes nos documentos do MEC e do IFSul e sentidos que gestores constroem para a nova política institucional em construção com a transformação em IF, tendo por referência os significantes ensino, pesquisa e extensão presentes nos textos. Para dar conta disso, o artigo está organizado da seguinte forma: a próxima seção trata do referencial teórico em que se baseia conceitualmente o artigo e fundamenta as análises apresentadas ao longo do texto; a seção três discute sentidos induzidos pela política e como os gestores constroem sentidos para sua ação cotidiana e a última seção discute os principais achados do estudo.

\section{O RECORTE TEÓRICO DA PESQUISA}

Tendo como linha condutora da pesquisa uma concepção complexa de políticas educacionais, em consonância com a matriz conceitual pós-estruturalista/ discursiva, foram utilizados aportes teóricos e metodológicos do ciclo de políticas, desenvolvido por Stephan Ball, e da Teoria do Discurso, de Ernesto Laclau.

Ball (1994) afirma que política é "um conjunto de tecnologias e práticas as quais são realizadas e disputadas em nível local. Política é ambos, texto e ação, palavras e fatos, tanto o que é intencionado como o que é realizado" (p.10). Assim, ao mesmo tempo em que uma política está sendo construída está sendo contestada e alterada: os "elaboradores/autores" não conseguem controlar o significado de uma determinada política, uma vez que elas serão interpretadas pelos agentes das diferentes arenas/níveis, criando novos significados para a referida política. Política é a própria razão de ser da existência do social, pois “aponta para estabelecer uma ordem, organizar a coexistência humana em condições sempre conflitivas" ligadas "ao antagonismo que se manifesta na diversidade das relações sociais” (MOUFFE, 1999, p.14).

Assume-se que as políticas estão constantemente em processo de deslocamento e fixação temporária, produzindo, nesse processo de construção, uma mescla de posicionamentos diversos, muitas vezes ambíguos. Dessa forma não é possível determinar a priori quais serão os resultados de uma determinada política quando esta estiver deslocada em outros contextos e submetida a 
releituras/reinterpretações de outros atores. Essa perspectiva é o motor deste trabalho.

Laclau e Mouffe (LACLAU; MOUFFE, 1987), no desenvolvimento da Teoria do Discurso (TD), consideram hegemonia o conceito chave para se pensar a política. Hegemonia é compreendida como a construção discursiva, a partir de um terreno de diferenças, em que um discurso específico passa a representar as demandas dessas diferenças, constituindo-as num bloco histórico de uma formação hegemônica específica, resultado de uma articulação, sem que nenhum conteúdo específico esteja, a priori, privilegiado a ocupar essa posição hegemônica.

Nesse referencial teórico, discurso não está relacionado apenas à fala e/ ou à escrita: envolve também a ação - e seus efeitos -, pois toda ação está imersa em uma significação. Nas palavras do próprio autor "os elementos linguísticos e não linguísticos não estão simplesmente justapostos e sim constituem um sistema diferencial e estruturado de posições - ou seja, um discurso" (LACLAU, MOUFFE, 1987, p.184)

No processo de constituição hegemônica, um discurso particular será selecionado e elevado à condição de discurso universal, representante de um processo de articulação e, portanto, responsável pela identidade, pela produção de sentidos, pelo estabelecimento das posições de sujeitos possíveis/permitidas para uma dada articulação.

Para que isso ocorra é necessário que uma demanda específica, num processo de articulação, consiga interpelar outros conjuntos de demandas, de modo que estas se reconheçam como partes daquela. Será necessário um esvaziamento do seu conteúdo mais literal - da particularidade representativa da demanda à qual estava associada - a fim de simbolizar o conjunto de demandas do momento e falar, agir, em nome do conjunto. É, pois, segundo Laclau, a capacidade de esvaziamento do conteúdo original de uma das demandas - da sua particularidade - para incorporar outras demandas particulares - representando uma totalidade contingente - que vai definir qual significante representa o processo hegemônico. Este esvaziamento é necessário, pois a articulação - e por consequência o discurso/o sistema de significação resultante desta articulação - são constituídos a partir de algo que está fora do sistema, num processo de antagonismo: não existe qualquer positividade, qualquer identidade positiva no sistema que seja capaz de tornar-se, por seu conteúdo específico, o objeto representativo do sistema.

É a competição entre diferenças internas de uma articulação que foi hegemonizada a partir de um exterior constitutivo para ocupar o universal com seus sentidos que faz que todo o processo hegemônico seja instável/contingente. A manutenção da hegemonia exige a constante manutenção de uma cadeia de 
equivalências, seja porque determinadas demandas não se considerem mais representadas por determinada articulação, por necessidade de incorporar novas demandas, expandindo a articulação, seja por alteração no exterior constitutivo desta articulação.

É o caráter aberto e incompleto de toda identidade social, resultante dessa lógica, que faz com que sentido e identidades sejam resultados do discurso hegemônico, que elimina a possibilidade a um sujeito transcendental/originário: o que existem são posições de sujeito, estabelecidas pelo discurso hegemonizado na articulação, o qual posiciona, autoriza, restringe os sujeitos que nele se constituem ou se expressam.

Por conseguinte, o discurso é resultado de uma construção social, que, ao mesmo tempo, constrói e expressa as relações sociais em determinado contexto, constituindo-se em todas as produções sociais das quais é expressão. A expressão prática discursiva refere-se a um discurso específico, num determinado contexto. Compreende-se dessa forma, por que os discursos - e por consequência as políticas, no contexto deste trabalho compreendidas como discursos - estão em constante processo de deslocamento e fixação temporária, produzindo posicionamentos diversos, muitas vezes contraditórios.

Consoante com os conceitos acima, assume-se que a linguagem constrói o mundo e, portanto, a atribuição de significado a um significante torna-se um processo cultural uma vez que "seu sentido somente poderá ser definido dentro de uma formação discursiva histórica e socialmente contingente" (LOPES; MACEDO, 2011, p.40).

Por fim, enfatiza-se que neste trabalho concebe-se política como discurso na concepção da TD por se entender que, em diferentes escalas, as políticas serão sempre construídas em processos hegemônicos, conforme possibilidades e limitações locais. A fim de evitar uma concepção hierarquizada no processo de deslocamento e ressignificação da política, adota-se o termo construção de políticas, independente da escala onde se insere a análise.

\section{OS SENTIDOS INTERPRETADOS DOS DOCUMENTOS E CONSTRUÍDOS PELOS GESTORES}

Os conceitos da Teoria do Discurso constituem a base teórica para os processos de análise do material empírico. Assim, a identificação das cadeias de equivalências (linguísticas e não linguísticas) em torno de pontos nodais (significantes privilegiados), a identificação dos Outros, das contingências e sedimentações (visíveis por meio dos significantes flutuantes, dos antagonismos e 
hegemonias presentes nos discursos) constitui elementos que permitem identificar e analisar os discursos e seus efeitos (JORGENSEN; PHILLIPS, 2002).

Por conseguinte, a identificação dos significantes privilegiados no material empírico é elemento fundamental para a identificação dos sentidos e a compreensão dos discursos. Inserido em uma pesquisa mais ampla na qual os significantes ensino, pesquisa e extensão foram escolhidos como significantes privilegiados no material empírico (ARAUJO, 2013), realiza-se, também neste trabalho, a interpretação de sentidos presentes em torno destes significantes nos documentos do MEC e do IFSul e nas entrevistas de gestores dos campi e da reitoria.

Todo o material empírico foi reorganizado e as sentenças nas quais esses significantes estavam presentes foram extraídas com o suporte do software WordSmith ${ }^{3}$. Ao se analisarem os discursos construídos em torno dos significantes ensino, pesquisa e extensão como categorias centrais, foi possível identificar outras categorias em torno destes, das quais se destacaram: articulação ensino, pesquisa e extensão; verticalização e integração, trabalho docente, gestão e, também, em consonância como o referencial teórico da análise, a construção de identidades discursivas para os IFs e para o IFSul.

Todas as sentenças foram reagrupadas em torno dessas categorias, enfatizando-se assim as aproximações e os afastamentos presentes na base de dados. É a partir desse processo que serão discutidos os sentidos presentes nos dois grupos de documentos e como os gestores da reitoria e dos campi constroem sentidos em seu cotidiano de trabalho ${ }^{4}$. A seguir, cada subseção representa a categoria em torno da qual foram agrupados os discursos, destacando-se os sentidos neles presentes. Pela extensão do material empírico, opta-se por não ilustrá-los apresentando recortes das falas dos sujeitos e dos documentos; o detalhamento está disponível na pesquisa já citada.

\subsection{Articulação ensino, pesquisa e extensão}

Os documentos do MEC assumem o princípio constitucional da indissociabilidade entre ensino, pesquisa e extensão. Entretanto, os sentidos para essa cadeia de equivalências - considerada capaz de potencializar a articulação

3 Ferramenta que trabalha com conceitos da Linguística de Corpus Desenvolvida por Mike Scott, em 1996, está atualmente na sexta versão. Disponível em: < http://www.lexically.net/wordsmith/version6/ index. html>. Acesso em: 01 fev. 2016

4

A contagem não foi utilizada como critério para determinar a relevância de determinados sentidos. 
com as forças sociais - vão flutuar, podendo representar a necessidade de atuação, a coexistência, o nivelamento ou a mesma hierarquia. A integração entre ciência, tecnologia e cultura, o foco na profissionalização e a tecnologia como elemento transversal são propostos como elementos viabilizadores para essa articulação.

No estatuto do IFSul, a articulação é significada por unidade entre ensino, pesquisa e extensão e, embora haja muitas ocorrências em cadeia das três dimensões, não há, ainda, fechamento de sentidos; nos documentos dos campi, entretanto, o que se observa é a preponderância da dimensão ensino.

Entre os gestores vinculados à reitoria observa-se o acolhimento dos discursos relativos à necessidade de inserção local e a construção de processos identitários que utiliza a universidade como exterior constitutivo - o Outro - para construção de identidade institucional das três dimensões. Entre os gestores dos campi, embora algumas vezes a dimensão ensino seja utilizada como o Outro para reforçar sentidos para pesquisa e extensão, existem construções de cadeias de equivalências entre os três significantes na expectativa de construção de uma nova forma de trabalhar que contemple a articulação - sem definir sentidos para esse significante - das três dimensões, com a expectativa que possa haver avanços substanciais na qualidade da aprendizagem.

\subsection{Cadeia de equivalência pesquisa e extensão}

Existem diversas construções discursivas em que pesquisa e extensão estão articuladas em conjunto. Diversas vezes elas se encontram em uma cadeia de equivalências usando a dimensão ensino como o Outro, especialmente quando se refere à estruturação dessas duas dimensões; outras vezes, a dimensão ensino é colocada na cadeia para apoiá-las em suas demandas. Como a maior parte das associações é de pesquisa e extensão, esta seção enfatiza os sentidos presentes em torno dessa cadeia de equivalências.

Os documentos do MEC partem do pressuposto de que o ensino é uma dimensão consolidada na rede federal e que é necessário consolidar a pesquisa e a extensão. Entretanto, pela variedade de possibilidades educacionais possíveis para os IFs, torna-se necessário desconstruir/problematizar esse discurso de consolidação da dimensão ensino: em geral, essa consolidação refere-se à educação profissional de nível médio e nem esse nível de ensino, pode ser considerado estabilizado, haja vista os conflitos históricos em torno da oferta dessa modalidade de ensino.

Institucionalmente, no processo de constituição das dimensões pesquisa e extensão, a presença da obrigatoriedade de atuação nessas dimensões presentes na legislação é acolhida para deslocar a estabilidade da dimensão ensino. Há 
discursos que constroem cadeias de equivalências entre as três dimensões, buscando compartilhar os recursos consolidados dessa dimensão e há discursos que utilizam ensino como o Outro para constituição identitária e para reivindicar recursos para essas duas dimensões. Em geral, nesse processo de constituição discursiva, pesquisa e extensão são justapostos em busca de reforço mútuo para suas demandas. Nessa cadeia estão presentes também os significantes inovação e pós-graduação.

Não há ainda sentidos hegemônicos para essas duas dimensões - pesquisa e extensão, conclusão originada da presença de sentidos diversos, tais como: são incipientes (na RFEP como um todo), a estruturação interna não vai ao encontro do que é esperado para os IFs, as dimensões estão na mesma situação, embora a pesquisa tenha começado a se institucionalizar antes e esteja mais bem estruturada. Atualmente, a falta de sentidos hegemônicos leva ao empoderamento da gestão na definição de diretrizes e ao foco em mecanismos de gestão e controle burocráticos. Nesse processo de construção de identidade, ao mesmo tempo em que são assumidos sentidos adotados por pesquisa e extensão universitária, procura-se caracterizar um afastamento da universidade por meio de discursos que sustentam que essas dimensões nos IFs devem ser diferentes daquelas instituições, exemplificados por meio de discursos que sustentam que os projetos em andamento no IFSul seriam pouco tecnológicos e os regramentos seriam academicistas, numa referência indireta à universidade.

\subsection{Extensão}

Nos documentos do MEC é muito evidente a associação desta dimensão com a possibilidade de diálogo efetivo e permanente com a sociedade. Extensão está relacionada com divulgação científica, acesso ao conhecimento e oportunidades educativas, embora haja um silenciamento em relação aos cursos de qualificação, elemento importante na oferta educacional dos IFs.

Os documentos do IFSul assumem como definição para essa dimensão aquela que foi pactuada pelo FORPROEX ${ }^{5}$, acolhendo os discursos de apoiar o desenvolvimento social, local e regional e registrando o compromisso com a oferta de cursos e desenvolvimento de projetos educacionais; associam extensão com divulgação científica, tecnológica e humanística. O significante sociedade flutua referindo-se a segmentos sociais, comunidade externa, comunidade em geral, mundo do trabalho, IFSul-empresa-sociedade, empresas e relações comunitárias, esses dois últimos heranças do modelo de relação com a sociedade

5 Fórum de Pró-Reitores de Extensão das Instituições Públicas de Educação Superior Brasileiras.

256 - RBPAE - v. 32, n. 1, p. 247 - 265 jan./abr. 2016 
existente na Escola Técnica e no CEFET-RS ${ }^{6}$. Indicativa da falta de consenso institucional sobre essa dimensão, não há ainda uma política de extensão aprovada pelo Conselho Superior, o que concentra as atividades da gestão no controle burocrático.

Os discursos dos gestores apontam para a falta de compreensão sobre o que seja extensão, embora destaquem que não deva ser a mesma coisa que extensão na universidade. A institucionalização dessa dimensão está no processo inicial e existem discursos de que há avanço na estrutura administrativa e no fomento enquanto outros argumentam que há pouco avanço, pois falta um olhar institucional e não tem estrutura. Entretanto, há o acolhimento de que essa dimensão vai mudar a instituição porque fortalece sua vinculação com as necessidades da sociedade, da comunidade, embora não esteja ainda na cultura institucional. Ao mesmo tempo em que assume o financiamento institucional como indicativo de superação do voluntarismo, responsabiliza os professores pelo estabelecimento dessa dimensão. Isto é representado por meio de discursos que argumentam que extensão é algo que está na cultura da pessoa, que já vem com a pessoa, referindo-se ao processo de formação universitária, em aproximação, novamente, com os sentidos da extensão universitária que, em outros discursos, busca um afastamento.

\subsection{Pesquisa}

Nos documentos do MEC o discurso central é que a pesquisa é processo fundamental para o desenvolvimento local, estando associada à inovação, a problemas concretos da comunidade, ao atendimento de necessidades, à democratização do conhecimento e ao compromisso com a humanidade.

Embora existam discursos que identifiquem a pesquisa como princípio científico, como princípio educativo e como processo de produção de conhecimento, a centralidade discursiva é na pesquisa aplicada, associada à melhoria das condições de vida da comunidade e das atividades produtivas locais, à garantia de ensino contextualizado e à superação da dicotomia ciência versus tecnologia e teoria versus prática.

Os documentos institucionais acolhem o discurso de que a pesquisa deve estabelecer à interação do IFSul com diferentes segmentos da sociedade, estendendo seus benefícios à comunidade, cuja flutuação foi discutida anteriormente. Assumem o compromisso com a pesquisa em todos os níveis de ensino, associando-a sempre à inovação e à pós-graduação. Diferentes

6 Denominações da instituição anteriores ao IFSul. 
qualificadores estão presentes na documentação: pesquisa acadêmica, pesquisa científica e tecnológica, pesquisa como principio educativo, pesquisa como processo educativo para investigação e produção de conhecimento, entretanto não acolhe "pesquisa aplicada", mesmo quando reproduz textos da legislação nos documentos oficiais. Tal como na extensão, não existem normas ou regulamentos recentes aprovados pelo Conselho Superior, o que é interpretado como indicativo da falta de hegemonização de determinados sentidos para a política institucional de pesquisa. Essa conclusão é reforçada pelo tratamento genérico das questões relacionadas a essa dimensão nos documentos mais recentes.

Nas entrevistas com os gestores é apontada como indicativo de um processo de institucionalização da pesquisa, o qual remonta à época de CEFET, a existência de grupos, projetos e bolsas de pesquisa. Em relação aos grupos de pesquisa há consenso de que são importantes para consolidação da pesquisa e da pós-graduação e embora existam muitos grupos cadastrados poucos estão consolidados. Os gestores argumentam que os processos de capacitação dos docentes em nível de pós-graduação favorecem a consolidação da pesquisa, pois os docentes mantêm vinculação com grupos de pesquisa das universidades onde estudaram e dão continuidade às pesquisas; contraditoriamente, há discursos de que os grupos de pesquisa são formados a partir dos interesses originados nos processos de formação e não no interesse institucional. Também existem discursos que apontam para a necessidade de criação de políticas de pesquisa para que esta não ocorra apenas por motivação dos servidores; há um acolhimento e uma oposição aos sentidos propostos por meio da pesquisa aplicada e é considerada positiva a existência de ações de pesquisas nos cursos técnicos de nível médio.

\subsection{Ensino}

Os documentos do MEC assumem que o ensino está consolidado na rede federal. A ênfase discursiva, entretanto, é na educação profissional de nível médio, especialmente na forma integrada, a qual é apresentada como solução para os problemas do ensino médio no país, possibilitando ampliação e universalização do acesso e melhorando a permanência dos estudantes, por meio de ensino contextualizado e significativo. No ensino superior, os discursos giram predominantemente em torno das licenciaturas e da formação de professores. Há silenciamento sobre outras possibilidades de formação de nível superior, incluindo a pós-graduação, e também sobre cursos de qualificação, embora existam algumas referências ao PROEJA.

Nos documentos institucionais os discursos associam o ensino à produção e à democratização do conhecimento e à formação de cidadãos capazes 
de tomar decisões responsáveis, ao qual deve integrar-se a pesquisa e a extensão. Em relação às licenciaturas, apenas acolhem o texto legal: a observação das ofertas educativas em nível superior indica que a prioridade são as engenharias nos campi Pelotas e Sapucaia do Sul e os cursos de viés tecnológico na maioria dos demais. Há comprometimento com oferta de EAD, a qual, entretanto, somente é viabilizada por meio de financiamento de órgãos de fomento, e existem cotas para escola pública, resultado de um processo de discussão interna anterior à obrigatoriedade legal; todavia, não existem outras políticas específicas para estudantes que acessaram a instituição por esse mecanismo.

Nos discursos dos gestores da reitoria há uma naturalização da prioridade institucional da dimensão ensino, indicando que ele é igual ao que era quando CEFET, com predominância discursiva na formação de nível médio. Há indícios da existência de embates entre novas possibilidades educacionais e determinada cultura institucional, indicando que há maior facilidade de inovação pedagógica nos novos campi. Uma contradição é percebida entre discursos que sustentam a existência de um ensino de qualidade e aqueles que questionam esta qualidade, indicando como justificativa, por exemplo, que ele não acompanha mercado de trabalho. Existem indicações de que as pessoas se envolvem nas discussões das questões relativas ao ensino, embora exista um silenciamento sobre PROEJA, FIC e pós-graduação.

Os sentidos entre os gestores dos campi não são muito diferentes: o ensino vem andando, já estava em movimento, funciona naturalmente; campus normal é associado às atividades de ensino, de sala de aula e o ensino tem prioridade em detrimento da pesquisa e da extensão. Entretanto, há discursos que apontam para o estabelecimento de uma nova cultura de ensino, em especial porque os cursos estariam incorporando questões locais, o que resulta em profissionais mais identificados com as questões regionais. Embora haja o acolhimento do discurso da profissionalização como solução para o ensino médio, há indicação de que se pensava mais nas metodologias de ensino enquanto ETFPel e CEFET. Também há problematização do significante qualidade o qual não pode ser associado apenas à existência de recursos e ao atendimento de indicadores (percebidos como números), devendo haver alteração nos processos em sala de aula.

\subsection{Verticalização e integração}

Nos documentos do MEC, esses significantes são vetores muito importantes na construção de uma nova política curricular a partir da criação dos IFs. Os sentidos construídos indicam que verticalização e integração entre níveis e modalidades de ensino garantem a construção de singularidades na 
arquitetura curricular dos IFs, permitem que os docentes atuem em diferentes níveis de ensino, associando teoria e prática e possibilitam que os estudantes compartilhem os espaços de aprendizagem (GRISCHKE, 2008). Conforme discutido anteriormente, a integração assume centralidade nos discursos da EP de nível médio, sendo apresentada como solução para os problemas do EM no país. Entretanto, nessa produção de sentidos para verticalização, há silenciamento sobre pós-graduação, e cursos de qualificação e os cursos PROEJA têm pouco espaço na produção de sentidos para integração.

Os documentos institucionais não assumem explicitamente a integração no EM, colocando-a no campo das possibilidades, em conjunto com todas as demais formas de organização da EP de nível médio. A verticalização, por sua vez, tem uma única ocorrência: apenas quando o documento institucional acolhe o texto legal.

Contudo, a verticalização volta a estar presente no discurso dos gestores em depoimentos que argumentam que: há lugar para os diversos níveis; tem-se que descobrir o lugar dos níveis; pessoas vão ter que trabalhar em diversos níveis; diminuem as tensões internas, está reduzindo-se a competição entre os diferentes níveis de ensino; é uma exigência do Termo de Acordo de Metas (TAM) ${ }^{7}$ para atingir o indicador de 20 estudantes por professor, entre outros. Entretanto, ainda que seja evidente a expansão da forma integrada na oferta educacional, há um silenciamento em torno do significante integrado.

\subsection{Trabalho docente}

Os discursos basicamente tensionam os docentes para que desempenhem novas funções: além do trabalho em atividades da dimensão ensino, o qual já vinha sendo ampliado para atendimento de diversos níveis, eles necessitam agora dar conta de demandas das dimensões pesquisa e extensão, em um contexto educacional predominante de ensino médio, onde há poucas referências para trabalhar com estas dimensões (GRISCHKE, 2013).

Culturalmente, tempo de trabalho em pesquisa e extensão não é considerado nos indicadores de tempo de trabalho dos professores - que leva em consideração tempo em sala de aula, preparação e reuniões pedagógicas - ainda que seja uma demanda em discussão há vários anos, em fase de implantação. A dificuldade do estabelecimento de uma política hegemônica se origina, provavelmente, pelo grande conjunto de demandas para o trabalho docente - há docentes que desejam trabalhar unicamente no nível médio ou no ensino superior,

$7 \quad$ O Termo de Acordo de Metas (TAM), contrato assinado entre os IFs e o MEC que estabelece indicadores institucionais.

260 - RBPAE - v. 32, n. 1, p. 247 - 265 jan./abr. 2016 
os que desejam trabalhar unicamente em atividades de ensino, os que também querem atuar em pesquisa ou extensão - e, também, pela pressão, em geral não explicita, pelo atendimento dos indicadores do TAM.

$\mathrm{Na}$ construção do processo de adesão dos professores às novas demandas de trabalho ${ }^{8}$, pesquisa e extensão são apresentadas como possibilidade de enriquecimento do trabalho; os professores são identificados com sentidos de que eles só querem dar aula e ir embora ou, contraditoriamente, não querem mais dar aula e somente atuar em pesquisa e extensão. Ainda que não explicitamente, usando esses mecanismos de cobrança e motivação, a gestão espera motivar e envolver os professores para que deem conta das novas demandas de trabalho, responsabilizando-os pela institucionalização das dimensões pesquisa e extensão. Nas entrevistas com professores, não enfatizadas neste trabalho, observou-se que os professores reagem de forma diferente a esse processo: alguns sentem-se intensificados outros não.

\subsection{Gestão}

Inicialmente, destaca-se que os documentos institucionais são pouco propositivos, com grande ocorrência dos verbos acompanhar, coordenar, incentivar, divulgar. Entretanto, não se pode desconsiderar que a estrutura institucional, presente nestes documentos, é poderosa na indução de sentidos, mesmo que não estejam explicitados no formato de texto.

A ausência de órgãos colegiados concentra as decisões na gestão. Não obstante exista um processo de proliferação de câmaras e núcleos, há centralidade na condução de processos de discussão a partir da reitoria. Como já se destacou, há dificuldades de fixação de sentidos para pesquisa e extensão, indicados por depoimentos que argumentam a insuficiência das políticas vigentes. Por conta disso, a gestão foca em controle e administração da burocracia, adotando a responsabilização dos professores como estratégia para dar conta das demandas dessas dimensões. Existem discursos de que as pessoas participam cada vez mais nas discussões, em especial as relativas à dimensão ensino, o que é apontado positivamente em muitos depoimentos; todavia, há sentidos que indicam uma expectativa de que a reitoria defina as políticas para que os campi apliquem.

Nesse processo de construção de identidades os documentos do MEC projetam diversos sentidos para o sujeito Instituto Federal: Instituição/Centro de Ensino, Pesquisa e Extensão; capacidade e qualidade de trabalho; fundamental para o desenvolvimento regional; o mundo do trabalho no seu código genético;

8 O destaque para pesquisa e extensão deve-se ao fato de que verticalização já era um processo em institucionalização com a cefetização, embora ainda produza conflitos internos em alguns campi. 
ensino público, gratuito, democrático e de excelência; capaz de derrubar as barreiras entre o ensino técnico e o científico; protagonista no ensino técnico, dando-lhe uma diretriz hoje inexistente.

Os discursos institucionais também projetam sentidos para o IFSul: instituição de qualidade; qualidade de ensino; dedicação e qualificação dos servidores; valorização do coletivo; uma das maiores instituições de ensino profissionalizante do país. Eles acolhem discursos que propõem a constituição de uma nova identidade, a diferenciação em relação à universidade (ensino diferente, pesquisa diferente, extensão diferente, carreira diferente) - a universidade operando como Outro para a constituição da identidade dos IFs -, a necessidade de inserção social e o ganho com o foco no atendimento à sociedade.

\section{CONSIDERAÇÕES FINAIS}

Assumindo que determinados significantes eram privilegiados na construção da realidade discursiva em torno da política do IFSul, na seção anterior discutiram-se sentidos presentes em documentos oficiais do MEC e o do IFSul e aqueles construídos pelos gestores em torno dos significantes ensino, pesquisa extensão. Além dessas categorias, outras que se destacaram como relevantes na análise foram articulação ensino, pesquisa e extensão; verticalização e integração; trabalho docente e gestão, onde se discutem identidades discursivas para os IFs e para o IFSul.

Ao assumir a complexidade como premissa para discussão da política, dialogando com Ball, compreendem-se os movimentos supostamente incoerentes que ocorrem em diferentes contextos, os quais produzem textos, de diversos tipos, inseridos um nos outros em um processo de bricolagem muitas vezes aparentemente sem lógica. Entretanto, com Laclau entende-se que essa aparente incoerência é o próprio processo de luta política de produção de sentidos, de significação, de acolhimento de demandas de diferentes grupos sociais.

Diferentes discursos, em variados espaços, partem do pressuposto de que o ensino está consolidado na rede federal. Entretanto, considerando-se os embates em torno da oferta de educação profissional de nível médio e os silenciamentos apontados na seção anterior, pode-se representar "ensino consolidado" como um mito, em diálogo com a teoria do discurso, o qual oculta conflitos e organiza espaços e relações sociais institucionais. Esse mito contribui para naturalizar a prioridade da dimensão ensino em relação à pesquisa e à extensão - visível institucionalmente por meio da estrutura administrativa, da valorização do tempo de trabalho e da destinação de recursos materiais e humanos - e também para 
certa estabilidade da oferta educacional de nível médio em detrimento dos demais níveis de ensino.

A verticalização e a integração são significantes centrais nos discursos representados nos documentos do MEC para a construção de uma nova política curricular para educação profissional no país. Entretanto, nos documentos institucionais eles estão praticamente ausentes e, mesmo que haja um silenciamento sobre a forma integrada, há uma crescente expansão desta na oferta educacional no IFSul. A verticalização, também ausente nos documentos institucionais, volta a estar presente nos discursos dos gestores na perspectiva de espaço para os diversos níveis, o que diminui tensões internas, ainda que se tenha que aprender a ajustar o currículo a cada nível. É importante enfatizar que em todos os discursos institucionais verticalização refere-se, predominantemente, à oferta de nível médio e ensino superior de graduação, existindo um silenciamento sobre oferta de pós-graduação e de cursos de qualificação (Ensino Fundamental).

A previsão de indissociabilidade ensino, pesquisa e extensão promove relevância discursiva - o empoderamento pela presença no texto legal - para as dimensões pesquisa e extensão na política curricular dos IFs. Interpreta-se que essas dimensões estão buscando construir sentidos de forma bastante similares: ainda que existam construções de cadeias de equivalência entre as dimensões ensino, pesquisa e extensão, o que se observa, em geral, é a construção de cadeias de equivalência entre pesquisa e extensão a fim de se reivindicarem avanços em suas demandas, muitas vezes utilizando a dimensão ensino como o Outro que impede a consolidação de suas identidades.

Pesquisa e extensão são percebidas institucionalmente como em movimento, em processo de consolidação institucional, o qual é justificado, ainda que com restrições, pela existência de estruturas administrativas para pesquisa e extensão, pela existência de financiamento institucional a essas atividades, pelo aumento do número de projetos de pesquisa e extensão e do número de grupos de pesquisas. Nesse contexto de consolidação, ambas as dimensões acolhem, institucionalmente, os discursos da ênfase no atendimento das necessidades locais, assumindo que podem contribuir para maior inserção da instituição na sociedade, significante este que flutua em todos os discursos, podendo representar desde grupos sociais em risco até mercado de trabalho.

Não há ainda políticas institucionais hegemônicas para pesquisa e extensão e a expectativa da gestão é de que os docentes deem conta da consolidação dessas dimensões. Os discursos da gestão indicam, em geral, que o processo de qualificação dos professores em nível de pós-graduação e a manutenção de vínculos com grupos de pesquisa nas instituições onde realizaram formação têm permitido o avanço, em especial, das atividades de pesquisa. Embora o 
financiamento institucional seja considerado relevante para que as atividades de pesquisa e extensão superem o que é denominado voluntariedade de trabalho dos professores, a não contabilização dessas atividades no tempo de trabalho (que tradicionalmente considera apenas tempo em sala de aula, preparação e reuniões pedagógicas) é indicativo da fragilidade institucional dessas dimensões. Considerase que, do ponto de vista do trabalho docente, há uma sobreposição das três dimensões, o que pode motivar o sentimento de intensificação pelos docentes. Do ponto de vista conceitual, os discursos institucionais para pesquisa e extensão, em especial para pesquisa, indicam aproximação com sentidos da pesquisa e extensão universitária. Eles indicam a cultura (universitária) dos docentes como elemento fundamental para fazer avançar essas dimensões.

Interpreta-se a "falta de política" para pesquisa e extensão, expressa em diversos depoimentos, como indicativo de um campo de luta para determinar sentidos institucionais para essas duas dimensões. Os indicadores da oferta educativa apontam uma instituição de atuação predominante na educação profissional de nível médio, com oferta muito restrita de pós-graduação. Entretanto, considerando-se a presença de sentidos que identificam pesquisa e extensão como qualificadoras no processo educacional de formação dos estudantes, acredita-se que a questão central a motivar a discussão de sentidos institucionais para essas dimensões seja: que sentidos para pesquisa e extensão podem ser construídos em uma instituição com atuação predominante no nível médio? É possível acolher sentidos do contexto universitário? Essas dimensões poderão ser institucionalizadas no IFSul por meio dos mesmos mecanismos que as colocam em movimento nas universidades?

\section{REFERÊNCIAS}

ARAUJO, Jair Jonko. Novos Sentidos das Políticas Curriculares para a Educação Profissional no Instituto Federal Sul-rio-grandense. 2013. 310p. Tese (Doutorado em Educação) - Universidade Federal de Pelotas, Pelotas, 2013.

BALL, Stephan. Education reform: a critical and post-structural approach. Buckingham: Open University Press, 1994.

BRASIL. Lei $\mathbf{n}^{\mathbf{0} 11.892}$, de 28 de dezembro de 2008. Dispõe sobre a criação dos Institutos Federais de Educação, Ciência e Tecnologia. Brasília: Imprensa Nacional, 2008

FLICK, Uwe. Desenho da pesquisa qualitativa. Porto Alegre: Artmed, 2009. 
GRISCHKE, Paulo. O Paradigma da Colaboração nas Políticas Públicas para a Educação Profissional e Suas Implicações sobre o Trabalho Docente. 2013. 401p. Tese (Doutorado em Educação) - Universidade Federal de Pelotas, Pelotas, 2013.

GRISCHKE, Paulo. O impacto das reestruturações produtivas e educacionais sobre o trabalho e a identidade docente: um estudo de caso do CEFET-RS. 2008. 210p. Dissertação (Mestrado em Educação) Universidade Federal de Pelotas. Pelotas-RG, 2008.

JORGENSEN, Marianne; PHILLIPS, Louise. Discourse Analysis as Theory and Method. London: SAGE Publications Ltd, 2002.

LACLAU, Ernesto; MOUFFE, Chantau. Hegemonia y Estrategía Socialista: hacia una radicalización de la democracia. Madrid: Siglo XXI, 1987.

LOPES, Alice Casimiro; MACEDO, Elizabeth. Teorias de Currículo. 1. ed. São Paulo: Cortez, 2011.

MEC/SETEC. Institutos Federais de Ciência, Educação e Tecnologia: concepção e diretrizes. Brasília: MEC, 2008. Disponível em:<http://portal.mec. gov.br/setec/arquivos/pdf3/ ifets_livreto.pdf>. Acesso: 10 mar. 2013.

MOUFFE, Chantau. El retorno de lo politico: comunidad, ciudadania, pluralismo y democracia radical. Buenos Aires: Paidos, 1999.

JAIR JONKO ARAUJO possui doutorado em Educação; professor no Instituto Federal Sul-rio-grandense (IFSul). E-mail: jair.jonko@gmail.com

ÁLVARO MOREIRA HYPÓLITO possui doutorado (PhD) em Curriculum and Instruction; Professor Associado na Universidade Federal de Pelotas (UFPel). E-mail: alvaro.hypolito@gmail.com 